\title{
Article \\ Changes in the Flower and Leaf Proteome of Common Buckwheat (Fagopyrum esculentum Moench) under High Temperature
}

\author{
Przemysław Kopeć $^{1}\left(\mathbb{D}\right.$, Marta Hornyák ${ }^{2}$, Jakub Pastuszak ${ }^{2} \oplus$, Anna Szczerba ${ }^{2}$, Marcin Rapacz ${ }^{2, *} \mathbb{D}$, Jacek Waga ${ }^{2}$ \\ and Agnieszka Płażek ${ }^{2}$ (D) \\ 1 Polish Academy of Sciences, Institute of Plant Physiology, Niezapominajek 21, 30-239 Kraków, Poland; \\ p.kopec@ifr-pan.edu.pl \\ 2 Department of Plant Breeding, Physiology and Seed Science, University of Agriculture, Podłużna 3, \\ 30-239 Kraków, Poland; marta.golebiewska@gmail.com (M.H.); jakub.pastuszak@urk.edu.pl (J.P.); \\ anna.szczerba21@gmail.com (A.S.); j.waga@urk.edu.pl (J.W.); rrplazek@cyf-kr.edu.pl (A.P.) \\ * Correspondence: rrrapacz@cyf-kr.edu.pl; Tel.: +48-124-253-301 (ext. 50)
}

check for

updates

Citation: Kopeć, P.; Hornyák, M.; Pastuszak, J.; Szczerba, A.; Rapacz, M.; Waga, J.; Płażek, A. Changes in the Flower and Leaf Proteome of Common Buckwheat (Fagopyrum esculentum Moench) under High Temperature. Int. J. Mol. Sci. 2021, 22, 2678. https://doi.org/10.3390/ ijms 22052678

Academic Editor: P. V. Vara Prasad

Received: 8 February 2021

Accepted: 4 March 2021

Published: 6 March 2021

Publisher's Note: MDPI stays neutral with regard to jurisdictional claims in published maps and institutional affiliations.

Copyright: (c) 2021 by the authors. Licensee MDPI, Basel, Switzerland. This article is an open access article distributed under the terms and conditions of the Creative Commons Attribution (CC BY) license (https:/ / creativecommons.org/licenses/by/ $4.0 /)$.

\begin{abstract}
Common buckwheat (Fagopyrum esculentum Moench), a pseudocereal crop, produces a large number of flowers, but this does not guarantee high seed yields. This species demonstrates strong abortion of flowers and embryos. High temperatures during the generative growth phase result in an increase in the degeneration of embryo sacs. The aim of this study was to investigate proteomic changes in flowers and leaves of two common buckwheat accessions with different degrees of heat tolerance, Panda and PA15. Two-dimensional gel electrophoresis and mass spectrometry techniques were used to analyze the proteome profiles. Analyses were conducted for flower buds, open flowers capable of fertilization, and wilted flowers, as well as donor leaves, i.e., those growing closest to the inflorescences. High temperature up-regulated the expression of 182 proteins. The proteomic response to heat stress differed between the accessions and among their organs. In the Panda accession, we observed a change in abundance of 17, 13, 28, and 11 proteins, in buds, open and wilted flowers, and leaves, respectively. However, in the PA15 accession there were 34, 21, 63, and 21 such proteins, respectively. Fifteen heat-affected proteins were common to both accessions. The indole-3-glycerol phosphate synthase chloroplastic-like isoform X2 accumulated in the open flowers of the heat-sensitive cultivar Panda in response to high temperature, and may be a candidate protein as a marker of heat sensitivity in buckwheat plants.
\end{abstract}

Keywords: common buckwheat; high temperature; proteomics; heat-affected proteins

\section{Introduction}

Common buckwheat (Fagopyrum esculentum Moench), which belongs to the Polygonaceae family, is a valuable source of rutin, iron, dietary fiber, and many other microelements. Buckwheat seeds do not contain gluten and have a well-balanced amino acid composition rich in lysine [1,2]. This species does not require good soil; however, it is sensitive to a number of environmental factors, such as frost and cold, high temperature, dry wind, and drought [3]. Its flowering biology is complex, as it is a heterostylic species that produces pin and thrum flowers. The flowers need to be cross-pollinated by insects, mainly bees. This plant is characterized by strong self-incompatibility. A single flower is able to be fertilized for one day only [4]. Buckwheat blooms throughout the growth season, but its abundant flower production (up to 2000 flowers per plant) does not guarantee high seed yields $[2,5,6]$. Our previous research showed that buckwheat plants have a limited ability to fill seeds, and hence this species shows a strong abortion of flowers and embryos [7].

In earlier investigations, we found that buckwheat plants at the vegetative phase develop much better at a higher temperature $\left(30{ }^{\circ} \mathrm{C}\right)$ than at $20^{\circ} \mathrm{C}$ [8]. However, $30^{\circ} \mathrm{C}$ is 
too warm for optimal embryo development [9]. In our previous work [9], we detected a significantly higher degree of embryo sac degeneration in plants grown at $30{ }^{\circ} \mathrm{C}$ than in plants grown at $20^{\circ} \mathrm{C}$.

High temperature negatively affects metabolic processes, protein structure, electron transport in cytoplasmic membranes, and the energy status of photosystems, while inducing the formation of reactive oxygen species (ROS) [10]. In addition, heat stress is associated with an enhanced risk of improper protein folding and denaturation of several intracellular and membrane proteins [11]. Heat leads to the increased expression of several proteins, especially those in the large heat-shock protein (HSP) family, which includes high molecular mass HSPs (from 6 to $110 \mathrm{kDa}$ ) and small HSPs (from 15 to $45 \mathrm{kDa}$ ) [11,12]. Proteomic analyses have shown that many other proteins are also synthesized in plants during adaptation to high temperature; examples include proteins involved in the antioxidant system [13-15], enzymes involved in biosynthesis of UDP-glucose, pyruvate dehydrogenase, transketolases, and enzymes in the Krebs cycle and pentose phosphate pathway that regenerate ribulose-1,5-bisphosphate (RuBP) and activate Rubisco [12].

Previous studies have focused on changes in proteomes during embryogenesis, fertilization, and seed formation [16]. Feng et al. [17] analyzed the proteome of Arabidopsis thaliana flowers, and proteins involved in protein synthesis, folding, modification and degradation, as well as a belonging to the regulatory system. Kerim et al. [18] analyzed the proteome of rice at several male gametophyte stages: the pollen mother cell tetrad, early young microspores, the early and late binucleate stages, and the heading stage. The proteins they observed, which played an important role in the development of the male gametophyte, were related to the metabolism of sugars, cell elongation and cell expansion. Although it is more difficult to analyze proteins in the female gametophyte because of technical difficulties, Uchiumi et al. [19] detected some proteins in rice eggs: the cytoplasmic glycolytic enzyme glyceraldehyde-3-phosphate dehydrogenase, histone $\mathrm{H} 4$, cytoplasmic ascorbate peroxidase, and a member of the HSP 90 subfamily. Feng et al. [17] detected differences in the abundance of pistil-proteins between compatible and self-incompatible Prunus armeniaca cultivars. Liu et al. [20] identified more than 40 proteins in aborted seeds, including three cysteine proteases that were possibly involved in programmed cell death. Das et al. [21] detected the differential expression of 44 abiotic stress-responsive proteins in soybean leaves under several abiotic stresses. The results and observations of those studies suggest that many differentially expressed photosynthesis-related proteins disrupt the regulation of Rubisco, electron transport, and the Calvin cycle during exposure to abiotic stresses.

The aim of this study was to investigate proteomic changes in flowers and leaves of two common buckwheat accessions, the Panda cultivar and the PA15 breeding line, which have different degrees of heat tolerance. In our previous study [9], we showed that Panda is more sensitive to heat stress than PA15. Our results showed that there were more degenerated embryo sacs at the flower bud formation stage at $30^{\circ} \mathrm{C}$ than at $20^{\circ} \mathrm{C}$ in Panda. By contrast, in PA15, the number of degenerated embryo sacs only increased after a longer duration of heat stress, i.e., at the open flower phase. In this study, we explored the proteomic changes during flower development, and the differences in proteomes between high temperature $\left(30^{\circ} \mathrm{C}\right)$ and control $\left(20^{\circ} \mathrm{C}\right)$ conditions. In our study, we mainly wanted to compare the stress-induced changes in the proteome in two accessions with different degrees of tolerance. On this occasion, we wanted to further identify heat-related proteins. To study the proteome we used two-dimensional electrophoresis in combination with liquid chromatography-mass spectrometry (nanoLC-MS/MS) and peptide mass fingerprinting (PMF). Although there have been advances in the methodology of proteome research in recent years, the methods used in our study are still adequate and widely used in studies similar to ours [22-25]. We identified proteins showing differences in abundance in response to heat in the two buckwheat accessions. Our results shed light on the mechanisms responsible for tolerance to heat stress, as manifested by a lower degree of degraded embryo sacs under high temperature. These analyses were performed for flower buds, open flowers 
capable of fertilization, and wilted flowers, as well as donor leaves, i.e., those growing closest to the inflorescences.

\section{Results}

\subsection{Protein Profiles in Flowers and Leaves}

In the 2-D electrophoresis analyses, different numbers of proteins were identified depending on the plant organ and the accession. Representative 2-D protein patterns are shown in Figure 1a. In the 2-D maps of flower bud proteins, we detected 1189 protein spots in Panda and 1159 in PA15. There were fewer protein spots in the 2-D maps produced from open flowers, namely 900 for Panda and 977 for PA15. In the 2-D maps produced from unpollinated wilted flowers, there were 1117 protein spots for Panda and 1097 for PA15. The smallest numbers of protein spots were detected in donor leaf samples, namely only 701 for Panda and 826 for PA15.

High temperature did not affect the number of protein spots within the accessions, but it affected the abundance of some proteins. In flower buds, high temperature up-regulated the expression of 17 proteins in Panda and 34 in PA15. Fewer proteins were up-regulated by heat in the open flowers: 13 in Panda and 21 in PA15. High temperature strongly affected the proteome of wilted flowers, up-regulating the expression of 28 proteins in Panda and 63 in PA15. In the donor leaves, heat stress affected the expression of 11 proteins in Panda and 20 in PA15. On the other hand, no downregulation of the expression of specific proteins as a result of high temperature was observed in any case.

The proteomic response to heat stress differed among plant organs and between the two accessions, as illustrated by heat maps and the results of hierarchical clustering analysis using Euclidean and Ward's linkage methods (Figure 1b). In Panda, only three proteins were commonly up-regulated by heat stress in different plant organs (in two out of four organs only). In PA15, eight proteins were commonly up-regulated by heat stress in two organs. A few proteins were commonly up-regulated in Panda and PA15 by heat stress, but most of the proteins up-regulated by heat stress differed between the two accessions. Venn diagrams illustrating these results are shown in Figure 1c. We detected four proteins up-regulated in buds of both accessions, one in open flowers, nine in wilted flowers, and one in donor leaves. In each accession, no proteins showed heat-inducible expression at all stages of flower development. In Panda, the abundance of spot 34 changed in the flower buds and wilted flowers in response to heat stress, and spots 57 and 60 were up-regulated by heat stress in open flowers and wilted flowers. In PA15, five protein spots (no. 14, 16, 18,20 , and 21) showed changes in abundance under heat stress in flower buds and open flowers, and three spots (no. 11, 31, and 33) showed changes in abundance under heat stress in flower buds and wilted flowers.

\subsection{Identification of Differentially Accumulated Proteins}

To qualitatively analyze the protein spots on the two-dimensional gel electrophoresis (2-DE) gels, 182 spots were excised from the gels and analyzed using nanoLC-MS/MS. Only 31 proteins were successfully identified and annotated with the functions of homologous proteins. Next, PMF analysis of protein spots that were not identified by nanoLC-MS/MS identified another 42 proteins. The results are listed in Table 1. For the remaining unidentified spots, searches were performed against the Swiss-Prot database, searching for proteins among all taxa. Based on the identified proteins, we searched for homologous proteins among green plants using the BLASTP program. This procedure allowed us to identify seven additional plant proteins (Table 2). 

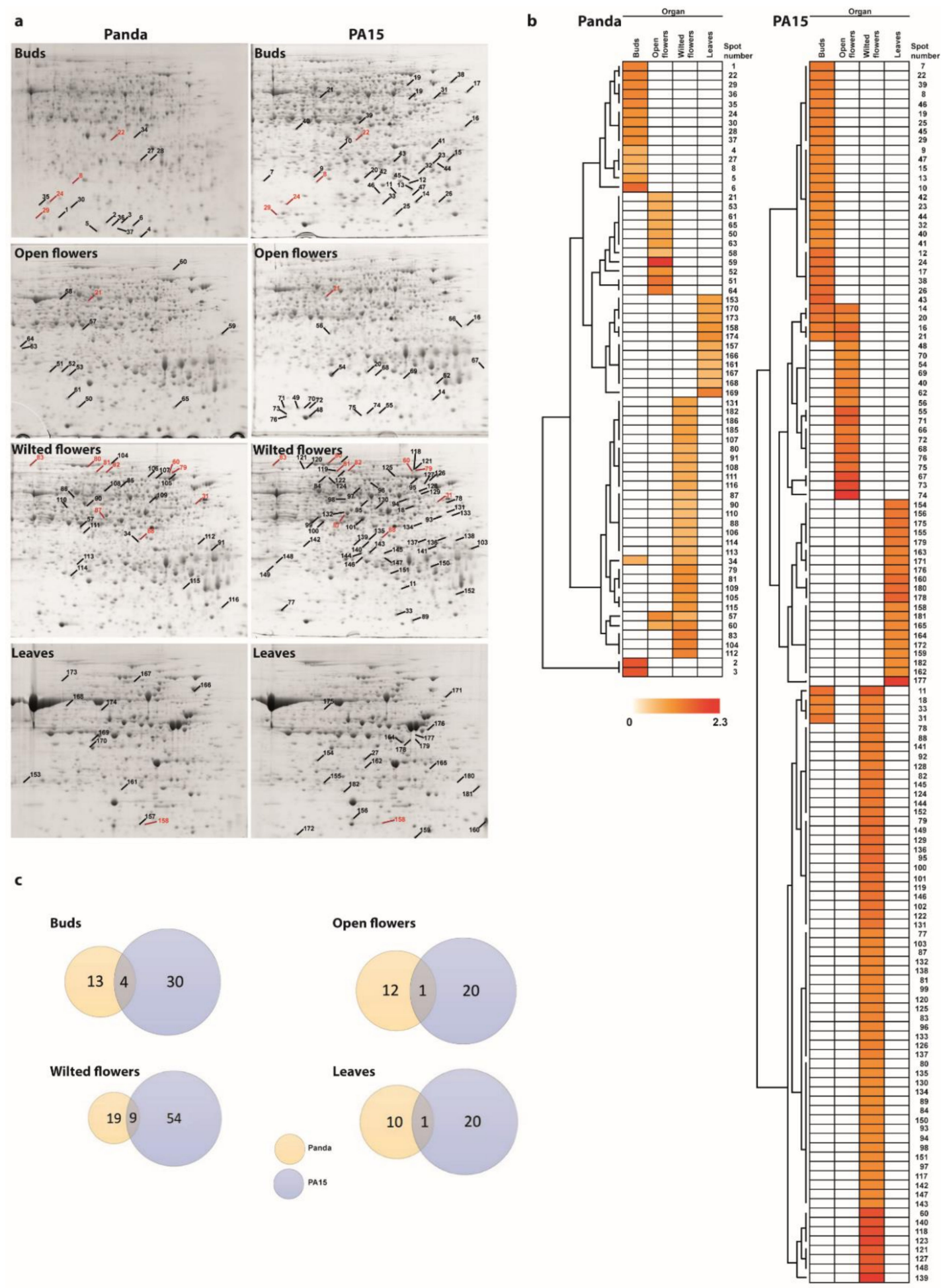

Figure 1. Changes induced by high temperature in proteomes of flower buds, open flowers, wilted flowers, and donor leaves of two common buckwheat accessions, Panda and PA15: (a) Representative two-dimensional gel electrophoresis (2-DE) gels of total proteins; proteins were separated by isoelectric focusing on an immobilized pH gradient IPG strip (pH 4-7) followed by sodium dodecyl sulfate (SDS)-PAGE on a 12\% acrylamide gel; marked spots are those showing changes in abundance in heat-stressed plants compared with control plants, red color indicate additionally proteins common for both Panda and PA15; (b) heatmaps illustrating the results of hierarchical clustering analysis using Euclidean and Ward's linkage methods; cluster analysis was conducted using PermutMatrix software v.1.9.3. (http://www.atgc-montpellier.fr/permutmatrix/); colors correspond to log-transformed values of protein spot fold-change; (c) Venn diagrams comparing proteome profiles (up-regulated proteins only) between two buckwheat accessions. 


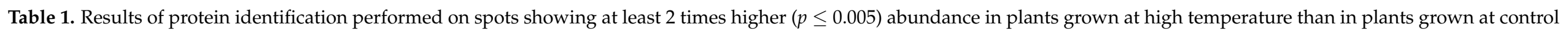
temperature. LC-MS/MS, liquid chromatography-mass spectrometry; PMF, mass fingerprinting.

\begin{tabular}{|c|c|c|c|c|c|c|c|c|c|c|}
\hline Spot No. ${ }^{a}$ & Organ $^{b}$ & Technique $^{\mathrm{c}}$ & UniProt No. ${ }^{d}$ & Protein Name ${ }^{e}$ & Reference Organism ${ }^{\mathrm{f}}$ & $\mathrm{M}_{\mathrm{t}}[\mathrm{kDa}]^{\mathrm{g}}$ & $\mathrm{pI}_{\mathrm{t}}{ }^{\mathrm{h}}$ & Protein Score $^{i}$ & Peptide Count ${ }^{j}$ & Coverage $(\%)^{k}$ \\
\hline 2 & B & LC-MS/MS & RS122_ARATH & $\begin{array}{l}40 \mathrm{~S} \text { ribosomal protein } \\
\text { S12-2 }\end{array}$ & Arabidopsis thaliana & 15.3 & 5.55 & 169.24 & 2 & 12.5 \\
\hline 4 & B & PMF & RL26_BRACM & $60 S$ ribosomal protein L26 & Brassica campestris & 16.9 & 11.60 & 135.90 & 4 & 8.9 \\
\hline 6 & B & PMF & CLDS_TOBAC & $\begin{array}{c}\text { Copal-8-ol } \\
\text { diphosphatehydratase, } \\
\text { chloroplastic }\end{array}$ & Nicotiana tabacum & 93.2 & 5.50 & 128.00 & 2 & 3.6 \\
\hline 7 & B & LC-MS/MS & PDRP2_ARATH & $\begin{array}{c}\text { Pyruvate, } \\
\text { phosphatedikinase } \\
\text { regulatory protein } 2\end{array}$ & Arabidopsis thaliana & 41.4 & 9.64 & 97.92 & 1 & 2.1 \\
\hline 8 & B & PMF & STAD6_ORYSI & $\begin{array}{l}\text { Acyl-[acyl-carrier-protein] } \\
\text { desaturase } 6 \text {, chloroplastic }\end{array}$ & $\begin{array}{l}\text { Oryza sativa subsp. } \\
\text { indica }\end{array}$ & 46.5 & 7.2 & 136.80 & 2 & 9.0 \\
\hline 9 & B & LC-MS/MS & PS4_PINST & $\begin{array}{c}\text { Putative LRR } \\
\text { diseaseresistance } \\
\text { protein/transmembrane } \\
\text { receptor kinase PS4 } \\
\text { (fragment) }\end{array}$ & Pinus strobus & 0.90 & 11.10 & 95.06 & 1 & 100.0 \\
\hline 10 & B & LC-MS/MS & AB5F_ARATH & $\begin{array}{l}\text { ABC transporter F family } \\
\text { member } 5\end{array}$ & Arabidopsis thaliana & 78 & 6.49 & 94.56 & 1 & 1.7 \\
\hline 13 & B & PMF & RHM2_ARATH & $\begin{array}{l}\text { Trifunctional UDP-glucose } \\
\text { 4,6-dehydratase/UDP-4- } \\
\text { keto-6-deoxy-D-glucose } \\
\text { 3,5-epimerase/UDP-4- } \\
\text { keto-L-rhamnose } \\
\text { reductase RHM2 }\end{array}$ & Arabidopsis thaliana & 75.2 & 6.00 & 116.70 & 1 & 2.4 \\
\hline 15 & B & LC-MS/MS & PSA5_ORYSJ & $\begin{array}{l}\text { Proteasome subunit alpha } \\
\text { type-5 }\end{array}$ & $\begin{array}{l}\text { Oryza sativa subsp. } \\
\quad \text { japonica }\end{array}$ & 26 & 4.60 & 557.20 & 11 & 37.1 \\
\hline 16 & $\mathrm{~B} ; \mathrm{OF}$ & PMF & UPL1_ARATH & $\begin{array}{l}\text { E3 ubiquitin-protein ligase } \\
\text { UPL1 }\end{array}$ & Arabidopsis thaliana & 404.7 & 4.80 & 126.20 & 3 & 1.3 \\
\hline 17 & B & LC-MS/MS & PSMD4_ARATH & $\begin{array}{l}\text { 26S proteasome } \\
\text { non-ATPase regulatory } \\
\text { subunit } 4 \text { homolog }\end{array}$ & Arabidopsis thaliana & 40.7 & 4.30 & 183.00 & 2 & 4.4 \\
\hline
\end{tabular}


Table 1. Cont.

\begin{tabular}{|c|c|c|c|c|c|c|c|c|c|c|}
\hline Spot No. ${ }^{a}$ & Organ $^{b}$ & Technique $^{c}$ & UniProt No. ${ }^{d}$ & Protein Name $^{\mathrm{e}}$ & Reference Organism ${ }^{\mathrm{f}}$ & $\mathrm{M}_{\mathrm{t}}[\mathrm{kDa}]^{\mathrm{g}}$ & $\mathrm{pI}_{\mathrm{t}}{ }^{\mathrm{h}}$ & Protein Score ${ }^{\mathrm{i}}$ & Peptide Count ${ }^{j}$ & Coverage $(\%)^{k}$ \\
\hline 18 & $\mathrm{~B} ; \mathrm{WF}$ & PMF & Y1765_ARATH & $\begin{array}{l}\text { Probable LRR receptor- } \\
\text { likeserine/threonine- } \\
\text { protein kinase } \\
\text { At1g07650 }\end{array}$ & Arabidopsis thaliana & 112.8 & 9.50 & 118.90 & 3 & 4.0 \\
\hline 20 & $\mathrm{~B} ; \mathrm{OF}$ & PMF & KN12D_ARATH & $\begin{array}{l}\text { Kinesin-like protein } \\
\text { KIN-12D }\end{array}$ & Arabidopsis thaliana & 314.9 & 5.10 & 118.00 & 3 & 1.3 \\
\hline 21 & $\mathrm{~B} ; \mathrm{OF}$ & LC-MS/MS & 6PGD1_SPIOL & $\begin{array}{l}\text { 6-phosphogluconate } \\
\text { dehydrogenase, } \\
\text { decarboxylating } 1\end{array}$ & Spinacia oleracea & 53.2 & 6.00 & 786.00 & 13 & 20.1 \\
\hline 22 & B & PMF & RL51_ARATH & $60 \mathrm{~S}$ ribosomal protein L5-1 & Arabidopsis thaliana & 34.3 & 9.70 & 130.40 & 3 & 11.6 \\
\hline 23 & B & PMF & QWRF4_ARATH & $\begin{array}{l}\text { QWRF motif-containing } \\
\text { protein } 4\end{array}$ & Arabidopsis thaliana & 66.9 & 10.20 & 123.00 & 3 & 4.2 \\
\hline 24 & B & PMF & GTL2_ARATH & $\begin{array}{l}\text { Trihelix transcription } \\
\text { factor GTL2 }\end{array}$ & Arabidopsis thaliana & 71.2 & 6.70 & 113.50 & 2 & 2.7 \\
\hline 25 & B & PMF & KN12F_ORYSJ & $\begin{array}{c}\text { Kinesin-like protein } \\
\text { KIN-12F }\end{array}$ & $\begin{array}{l}\text { Oryza sativa subsp. } \\
\text { japonica }\end{array}$ & 317.1 & 5.00 & 137.70 & 5 & 2.0 \\
\hline 26 & B & PMF & MYB98_ARATH & $\begin{array}{c}\text { Transcription factor } \\
\text { MYB98 }\end{array}$ & Arabidopsis thaliana & 50.1 & 6.10 & 129.70 & 4 & 6.8 \\
\hline 27 & B & LC-MS/MS & TPIC_ARATH & $\begin{array}{c}\text { Triosephosphate } \\
\text { isomerase, chloroplastic }\end{array}$ & Arabidopsis thaliana & 33.3 & 8.90 & 355.70 & 5 & 16.5 \\
\hline 28 & B & LC-MS/MS & IPYR2_ARATH & $\begin{array}{c}\text { Soluble inorganic } \\
\text { pyrophosphatase } 2\end{array}$ & Arabidopsis thaliana & 24.7 & 5.70 & 125.80 & 1 & 5.5 \\
\hline 33 & $\mathrm{~B} ; \mathrm{WF}$ & LC-MS/MS & ADF2_ORYSJ & $\begin{array}{c}\text { Actin-depolymerizing } \\
\text { factor } 2\end{array}$ & $\begin{array}{l}\text { Oryza sativa subsp. } \\
\text { japonica }\end{array}$ & 16.8 & 5.60 & 102.50 & 1 & 8.3 \\
\hline 48 & OF & LC-MS/MS & AB2C_ARATH & $\begin{array}{c}\mathrm{ABC} \text { transporter } \mathrm{C} \text { family } \\
\text { member } 2\end{array}$ & Arabidopsis thaliana & 182 & 6.00 & 103.88 & 0 & 0.0 \\
\hline 49 & OF & PMF & HXK4_ORYSJ & $\begin{array}{c}\text { Hexokinase-4, } \\
\text { chloroplastic }\end{array}$ & $\begin{array}{l}\text { Oryza sativa subsp. } \\
\text { japonica }\end{array}$ & 54.7 & 6.50 & 122.80 & 3 & 6.5 \\
\hline 51 & $\mathrm{OF}$ & PMF & SWTIE_ARATH & Protein SWEETIE & Arabidopsis thaliana & 244.2 & 5.10 & 123.00 & 3 & 1.8 \\
\hline 52 & OF & PMF & CALS2_ARATH & Callosesynthase 2 & Arabidopsis thaliana & 225.9 & 9.20 & 132.50 & 4 & 1.9 \\
\hline 53 & OF & LC-MS/MS & PS4_PINST & $\begin{array}{c}\text { Putative LRR } \\
\text { diseaseresistance } \\
\text { protein/transmembrane } \\
\text { receptor kinase PS4 } \\
\text { (fragment) }\end{array}$ & Pinus strobus & 0.90 & 11.10 & 90.53 & 1 & 100.0 \\
\hline
\end{tabular}


Table 1. Cont.

\begin{tabular}{|c|c|c|c|c|c|c|c|c|c|c|}
\hline Spot No. ${ }^{a}$ & Organ $^{b}$ & Technique $^{\mathrm{c}}$ & UniProt No. ${ }^{d}$ & Protein Name ${ }^{e}$ & Reference Organism $^{\mathrm{f}}$ & $\mathrm{M}_{\mathrm{t}}[\mathrm{kDa}]^{\mathrm{g}}$ & $\mathrm{pI}_{\mathrm{t}}{ }^{\mathrm{h}}$ & Protein Score ${ }^{i}$ & Peptide Count ${ }^{j}$ & Coverage $(\%)^{k}$ \\
\hline 54 & OF & LC-MS/MS & ZDHC8_ARATH & $\begin{array}{c}\text { Probable protein } \\
\text { S-acyltransferase } 20\end{array}$ & Arabidopsis thaliana & 76.8 & 9.60 & 123.05 & 2 & 2.4 \\
\hline 57 & OF; WF & PMF & MDHC2_ARATH & $\begin{array}{c}\text { Malate dehydrogenase 2, } \\
\text { cytoplasmic }\end{array}$ & Arabidopsis thaliana & 35.7 & 6.30 & 466.10 & 8 & 26.8 \\
\hline 58 & $\mathrm{OF}$ & PMF & UGDH2_ARATH & $\begin{array}{c}\text { UDP-glucose } \\
\text { 6-dehydrogenase } 2\end{array}$ & Arabidopsis thaliana & 53.1 & 5.60 & 162.80 & 3 & 7.7 \\
\hline 60 & OF; WF & LC-MS/MS & HSP70_MAIZE & Heatshock $70 \mathrm{kDa}$ protein & Zea mays & 70.5 & 5.10 & 470.40 & 8 & 14.7 \\
\hline 61 & OF & PMF & AUG8_ARATH & AUGMIN subunit 8 & Arabidopsis thaliana & 69.8 & 10.70 & 117.50 & 4 & 5.7 \\
\hline 77 & WF & PMF & RLT2_ARATH & $\begin{array}{l}\text { Homeobox-DDT domain } \\
\text { protein RLT2 }\end{array}$ & Arabidopsis thaliana & 190.3 & 5.30 & 116.30 & 4 & 2.2 \\
\hline 78 & WF & PMF & RCA_MALDO & $\begin{array}{l}\text { Ribulose bisphosphate } \\
\text { carboxylase/oxygenase } \\
\text { activase, chloroplastic }\end{array}$ & Malus domestica & 48 & 8.20 & 277.70 & 5 & 13.5 \\
\hline 79 & WF & PMF & HSP7N_ARATH & $\begin{array}{l}\text { Heatshock } 70 \mathrm{kDa} \text { protein } \\
18\end{array}$ & Arabidopsis thaliana & 68.3 & 5.20 & 539.30 & 7 & 16.4 \\
\hline 80 & WF & PMF & CLPC_PEA & $\begin{array}{c}\text { Chaperone protein } \mathrm{ClpC}, \\
\text { chloroplastic }\end{array}$ & Pisum sativum & 102.6 & 6.50 & 853.70 & 16 & 16.3 \\
\hline 82 & WF & PMF & DEK1_ARATH & $\begin{array}{l}\text { Calpain- } \\
\text { typecysteineprotease } \\
\text { DEK1 }\end{array}$ & Arabidopsis thatiana & 238.1 & 6.10 & 131.20 & 4 & 2.4 \\
\hline 83 & WF & PMF & GLR34_ARATH & Glutamate receptor 3.4 & Arabidopsis thaliana & 107.1 & 9.10 & 120.00 & 4 & 5.0 \\
\hline 84 & WF & PMF & C76AD_BETVU & Cytochrome P450 76AD1 & Beta vulgaris & 56.2 & 8.10 & 133.30 & 3 & 4.6 \\
\hline 85 & WF & PMF & ILV5_ARATH & $\begin{array}{c}\text { Ketol-acid } \\
\text { reductoisomerase, } \\
\text { chloroplastic }\end{array}$ & Arabidopsis thatiana & 63.8 & 6.40 & 181.00 & 2 & 4.9 \\
\hline 86 & WF & PMF & Y5537_ARATH & $\begin{array}{l}\text { G-typelectin S-receptor- } \\
\text { likeserine/threonine- } \\
\text { protein kinase } \\
\text { At5g35370 }\end{array}$ & Arabidopsis thaliana & 96 & 6.60 & 127.20 & 3 & 4.5 \\
\hline 87 & WF & LC-MS/MS & PGKY_TOBAC & $\begin{array}{l}\text { Phosphoglycerate kinase, } \\
\text { cytosolic }\end{array}$ & Nicotiana tabacum & 42.3 & 5.60 & 557.90 & 10 & 28.9 \\
\hline
\end{tabular}


Table 1. Cont.

\begin{tabular}{|c|c|c|c|c|c|c|c|c|c|c|}
\hline Spot No. ${ }^{a}$ & Organ $^{b}$ & Technique $^{c}$ & UniProt No. ${ }^{d}$ & Protein Name $^{\mathrm{e}}$ & Reference Organism ${ }^{f}$ & $\mathrm{M}_{\mathrm{t}}[\mathrm{kDa}]^{\mathrm{g}}$ & $\mathrm{pI}_{\mathrm{t}}{ }^{\mathrm{h}}$ & Protein Score $^{\mathrm{i}}$ & Peptide Count ${ }^{j}$ & Coverage (\%) ${ }^{k}$ \\
\hline 88 & WF & PMF & ALFP2_ARATH & $\begin{array}{c}\text { Fructose- } \\
\text { bisphosphatealdolase 2, } \\
\text { chloroplastic }\end{array}$ & Arabidopsis thaliana & 43 & 6.80 & 451.50 & 8 & 15.8 \\
\hline 89 & WF & PMF & SMC3_ARATH & $\begin{array}{l}\text { Structural maintenance of } \\
\text { chromosomes protein } 3\end{array}$ & Arabidopsis thaliana & 139.3 & 6.10 & 124.50 & 4 & 2.9 \\
\hline 91 & WF & LC-MS/MS & 1433_HELAN & 14-3-3-like protein & Helianthus annuus & 28.9 & 4.50 & 356.30 & 6 & 19.7 \\
\hline 92 & WF & LC-MS/MS & HSP7C_PETHY & $\begin{array}{l}\text { Heatshock cognate } 70 \mathrm{kDa} \\
\text { protein }\end{array}$ & Petunia hybrida & 71.2 & 5.00 & 1145.10 & 20 & 30.7 \\
\hline 95 & WF & LC-MS/MS & GDI_ARATH & $\begin{array}{c}\text { Guanosine nucleotide } \\
\text { diphosphate dissociation } \\
\text { inhibitor }\end{array}$ & Arabidopsis thaliana & 49.5 & 5.00 & 266.90 & 5 & 10.1 \\
\hline 96 & WF & LC-MS/MS & PMG2_ARATH & $\begin{array}{c}\text { Probable } \\
\text { 2,3-bisphosphoglycerate- } \\
\text { independent } \\
\text { phosphoglyceratemutase 2 }\end{array}$ & Arabidopsis thaliana & 60.7 & 5.50 & 267.00 & 3 & 6.8 \\
\hline 97 & WF & LC-MS/MS & PMGI_MESCR & $\begin{array}{l}\text { 2,3-bisphosphoglycerate- } \\
\text { independent } \\
\text { phosphoglycerate mutase }\end{array}$ & $\begin{array}{l}\text { Mesembryanthemum } \\
\text { crystallinum }\end{array}$ & 61.1 & 5.30 & 340.60 & 6 & 12.7 \\
\hline 98 & WF & LC-MS/MS & RH15_ARATH & $\begin{array}{c}\text { DEAD-box } \\
\text { ATP-dependent RNA } \\
\text { helicase } 15\end{array}$ & Arabidopsis thaliana & 48.3 & 5.30 & 369.40 & 6 & 12.6 \\
\hline 99 & WF & LC-MS/MS & ALF_ORYSJ & $\begin{array}{l}\text { Fructose-bisphosphate } \\
\text { aldolase cytoplasmic } \\
\text { isozyme }\end{array}$ & $\begin{array}{l}\text { Oryza sativa subsp. } \\
\quad \text { japonica }\end{array}$ & 38.8 & 7.70 & 254.80 & 4 & 7.8 \\
\hline 100 & WF & LC-MS/MS & GLYG1_SOYBN & Glycinin G1 & Glycine max & 55.7 & 5.80 & 394.60 & 8 & 21.0 \\
\hline 101 & WF & LC-MS/MS & UPTG_MAIZE & $\begin{array}{l}\text { Alpha-1,4-glucan-protein } \\
\text { synthase [UDP-forming] }\end{array}$ & Zea mays & 41.2 & 5.70 & 423.00 & 9 & 27.7 \\
\hline 102 & WF & LC-MS/MS & PSA1_ORYSJ & $\begin{array}{c}\text { Proteasome subunit alpha } \\
\text { type- } 1\end{array}$ & $\begin{array}{l}\text { Oryza sativa subsp. } \\
\text { japonica }\end{array}$ & 29.6 & 5.60 & 151.70 & 2 & 10.0 \\
\hline 153 & $\mathrm{~L}$ & LC-MS/MS & CAHC_TOBAC & $\begin{array}{l}\text { Carbonic anhydrase, } \\
\text { chloroplastic }\end{array}$ & Nicotiana tabacum & 34.5 & 6.46 & 139.33 & 1 & 3.1 \\
\hline 154 & $\mathrm{~L}$ & LC-MS/MS & CAHC_TOBAC & $\begin{array}{l}\text { Carbonic anhydrase, } \\
\text { chloroplastic }\end{array}$ & Nicotiana tabacum & 34.5 & 6.46 & 110.55 & 1 & 5.6 \\
\hline
\end{tabular}


Table 1. Cont.

\begin{tabular}{|c|c|c|c|c|c|c|c|c|c|c|}
\hline Spot No. ${ }^{a}$ & Organ $^{b}$ & Technique $^{c}$ & UniProt No. ${ }^{d}$ & Protein Name $^{\mathrm{e}}$ & Reference Organism ${ }^{f}$ & $\mathrm{M}_{\mathrm{t}}[\mathrm{kDa}]^{\mathrm{g}}$ & $\mathrm{pI}_{\mathrm{t}}{ }^{\mathrm{h}}$ & Protein Score $^{\mathrm{i}}$ & Peptide Count ${ }^{j}$ & Coverage (\%) ${ }^{k}$ \\
\hline 158 & $\mathrm{~L}$ & PMF & METK_CAMSI & $\begin{array}{l}\text { S-adenosylmethionine } \\
\text { synthase }\end{array}$ & Camellia sinensis & 42.8 & 5.20 & 150.70 & 3 & 6.9 \\
\hline 160 & $\mathrm{~L}$ & PMF & PP207_ARATH & $\begin{array}{l}\text { Pentatricopeptide } \\
\text { repeat-containing protein } \\
\text { At3g02330, mitochondrial }\end{array}$ & Arabidopsis thaliana & 101.6 & 6.00 & 128.60 & 3 & 4.9 \\
\hline 161 & $\mathrm{~L}$ & PMF & CHR4_ARATH & $\begin{array}{l}\text { Protein CHROMATIN } \\
\text { REMODELING } 4\end{array}$ & Arabidopsis thaliana & 247.8 & 5.90 & 128.70 & 4 & 3.2 \\
\hline 162 & $\mathrm{~L}$ & LC-MS/MS & CAHC_PEA & $\begin{array}{c}\text { Carbonic anhydrase, } \\
\text { chloroplastic }\end{array}$ & Pisum sativum & 35.4 & 7.74 & 263.63 & 1 & 5.5 \\
\hline 163 & $\mathrm{~L}$ & LC-MS/MS & CDSP_ARATH & $\begin{array}{l}\text { Thioredoxin-like protein } \\
\text { CDSP32, chloroplastic }\end{array}$ & Arabidopsis thaliana & 33.7 & 9.40 & 214.50 & 3 & 7.9 \\
\hline 164 & $\mathrm{~L}$ & LC-MS/MS & CYSKP_SPIOL & $\begin{array}{l}\text { Cysteine synthase, chloro- } \\
\text { plastic/chromoplastic }\end{array}$ & Spinacia oleracea & 40.6 & 7.60 & 211.70 & 4 & 12.5 \\
\hline 165 & $\mathrm{~L}$ & PMF & CRK20_ARATH & $\begin{array}{l}\text { Putativecysteine-rich } \\
\text { receptor-like protein } \\
\text { kinase } 20\end{array}$ & Arabidopsis thaliana & 74 & 6.60 & 118.50 & 3 & 7.1 \\
\hline 166 & $\mathrm{~L}$ & PMF & RUB2_BRANA & $\begin{array}{c}\text { RuBisCO large } \\
\text { subunit-binding protein } \\
\text { subunit alpha, } \\
\text { chloroplastic }\end{array}$ & Brassica napus & 61.6 & 5.00 & 569.20 & 9 & 15.8 \\
\hline 167 & $\mathrm{~L}$ & PMF & TKTC_SPIOL & $\begin{array}{l}\text { Transketolase, } \\
\text { chloroplastic }\end{array}$ & Spinacia oleracea & 80.2 & 6.20 & 262.90 & 5 & 6.5 \\
\hline 168 & $\mathrm{~L}$ & PMF & HUAL1_ARATH & Protein HUA2-LIKE 1 & Arabidopsis thaliana & 156.5 & 8.90 & 113.20 & 3 & 2.4 \\
\hline 169 & $\mathrm{~L}$ & PMF & GRDP1_ARATH & $\begin{array}{c}\text { Glycine-richdomain- } \\
\text { containing protein } \\
1\end{array}$ & Arabidopsis thaliana & 89.4 & 6.60 & 129.60 & 5 & 6.7 \\
\hline 170 & $\mathrm{~L}$ & PMF & FENR1_ORYSI & $\begin{array}{l}\text { Ferredoxin-NADP } \\
\text { reductase, leaf isozyme 1, } \\
\text { chloroplastic }\end{array}$ & $\begin{array}{l}\text { Oryza sativa subsp. } \\
\text { indica }\end{array}$ & 40 & 8.70 & 192.90 & 3 & 7.7 \\
\hline 171 & $\mathrm{~L}$ & PMF & KN12F_ORYSJ & $\begin{array}{c}\text { Kinesin-like protein } \\
\text { KIN-12F }\end{array}$ & $\begin{array}{l}\text { Oryza sativa subsp. } \\
\text { japonica }\end{array}$ & 317.1 & 5.00 & 123.70 & 4 & 1.9 \\
\hline
\end{tabular}


Table 1. Cont.

\begin{tabular}{|c|c|c|c|c|c|c|c|c|c|c|}
\hline Spot No. ${ }^{a}$ & Organ $^{b}$ & Technique $^{c}$ & UniProt No. $^{d}$ & Protein Name $^{\mathrm{e}}$ & Reference Organism ${ }^{f}$ & $\mathrm{M}_{\mathrm{t}}[\mathrm{kDa}]^{\mathrm{g}}$ & $\mathrm{pI}_{\mathrm{t}}{ }^{\mathrm{h}}$ & Protein Score ${ }^{i}$ & Peptide Count ${ }^{j}$ & Coverage $(\%)^{k}$ \\
\hline 172 & $\mathrm{~L}$ & PMF & GLTB2_ARATH & $\begin{array}{c}\text { Ferredoxin-dependent } \\
\text { glutamatesynthase 2, } \\
\text { chloroplastic }\end{array}$ & Arabidopsis thaliana & 177.6 & 6.60 & 128.00 & 4 & 2.8 \\
\hline
\end{tabular}

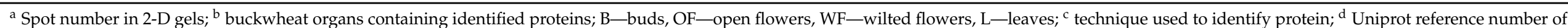

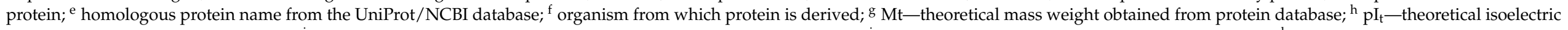

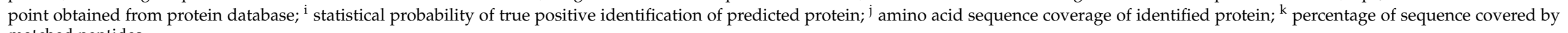
matched peptides.

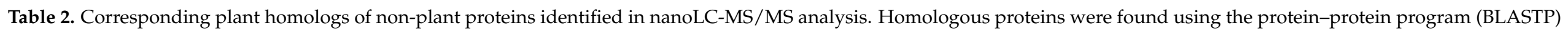
at NCBInr.

\begin{tabular}{|c|c|c|c|c|c|c|c|c|c|c|c|c|c|c|}
\hline Spot No. ${ }^{a}$ & Organ $^{b}$ & UniProt No. & Protein Name ${ }^{c}$ & $\begin{array}{l}\text { Reference } \\
\text { Organism }^{d}\end{array}$ & $\begin{array}{c}\mathrm{M}_{\mathrm{t}}^{\mathrm{e}} \\
{[\mathrm{kDa}]}\end{array}$ & $\mathrm{pI}_{\mathrm{t}}{ }^{\mathrm{f}}$ & $\begin{array}{l}\text { Protein } \\
\text { Score }{ }^{g}\end{array}$ & $\begin{array}{l}\text { Peptide } \\
\text { Count }\end{array}$ & $\begin{array}{c}\text { Coverage } \\
{[\%]^{\mathrm{i}}}\end{array}$ & $\begin{array}{c}\text { Homologous Protein } \\
\text { Name }^{j}\end{array}$ & NCBI No. & $\begin{array}{l}\text { Reference } \\
\text { Organism }\end{array}$ & $I^{k}$ & $\mathbf{P}^{1}$ \\
\hline 3 & B & CAPZA_KLULA & $\begin{array}{l}\text { F-actin-capping protein } \\
\text { subunit alpha }\end{array}$ & $\begin{array}{c}\text { Kluyveromyces } \\
\text { lactis }\end{array}$ & 29.9 & 4.54 & 99.31 & 1 & 4.2 & $\begin{array}{l}\text { F-actin-capping protein } \\
\text { subunit alpha-like }\end{array}$ & XP_023907009.1 & $\begin{array}{l}\text { Quercus } \\
\text { suber }\end{array}$ & $33 \%$ & $53 \%$ \\
\hline 11 & $\mathrm{~B} ; \mathrm{WF}$ & MTNC_GLUDA & Enolase-phosphatase E1 & $\begin{array}{l}\text { Gluconacetobacter } \\
\text { diazotrophicus }\end{array}$ & 24.9 & 4.97 & 97.57 & 1 & 3.0 & $\begin{array}{c}\text { Probable bifunctional } \\
\text { methylthioribulose-1- } \\
\text { phosphate } \\
\text { dehydratase/enolase- } \\
\text { phosphatase E1 1 }\end{array}$ & XP_028794642.1 & Prosopis alba & $39 \%$ & $53 \%$ \\
\hline 19 & B & IF2_THEFY & $\begin{array}{l}\text { Translation initiation } \\
\text { factor IF-2 }\end{array}$ & $\begin{array}{l}\text { Thermobifida } \\
\text { fusca }\end{array}$ & 100.5 & 9.82 & 101.74 & 1 & 1.2 & $\begin{array}{l}\text { Translation initiation factor } \\
\text { IF-2, chloroplastic }\end{array}$ & GEZ89434.1 & $\begin{array}{l}\text { Tanacetum } \\
\text { cinerari- } \\
\text { ifolium }\end{array}$ & $52 \%$ & $71 \%$ \\
\hline 50 & OF & MURA_PSEU5 & $\begin{array}{c}\text { UDP-N- } \\
\text { acetylglucosamine } \\
\text { 1-carboxy- } \\
\text { vinyltransferase }\end{array}$ & $\begin{array}{l}\text { Pseudomonas } \\
\text { stutzer }\end{array}$ & 44.6 & 5.62 & 94.32 & 1 & 2.1 & $\begin{array}{c}\text { Glutamate synthase } 1 \\
\text { [NADH], chloroplastic } \\
\text { isoform X1 }\end{array}$ & GEU28314.1 & $\begin{array}{l}\text { Tanacetum } \\
\text { cinerari- } \\
\text { ifolium }\end{array}$ & $59 \%$ & $74 \%$ \\
\hline 56 & OF & LEXA_MYXXD & LexA repressor & $\begin{array}{l}\text { Myxococcus } \\
\text { xanthus }\end{array}$ & 24.7 & 9.29 & 99.27 & 1 & 5.4 & $\begin{array}{l}\text { DNA-3-methyladenine } \\
\text { glycosylase } 1\end{array}$ & GEX09398.1 & $\begin{array}{l}\text { Tanacetum } \\
\text { cinerari- } \\
\text { ifolium }\end{array}$ & $37 \%$ & $58 \%$ \\
\hline 59 & OF & TRPC_ACIF2 & $\begin{array}{l}\text { Indole-3-glycerol } \\
\text { phosphate synthase }\end{array}$ & $\begin{array}{l}\text { Acidithiobacillus } \\
\text { ferrooxidans }\end{array}$ & 28.7 & 5.02 & 101.36 & 1 & 3.4 & $\begin{array}{l}\text { Indole-3-glycerol phosphate } \\
\text { synthase, chloroplastic-like } \\
\text { isoform X2 }\end{array}$ & XP_026448585.1 & $\begin{array}{l}\text { Physcomitrella } \\
\text { patens }\end{array}$ & $48 \%$ & $63 \%$ \\
\hline
\end{tabular}

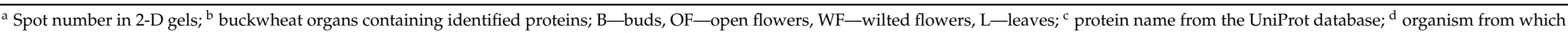

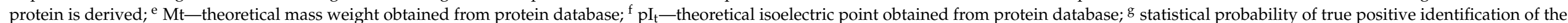

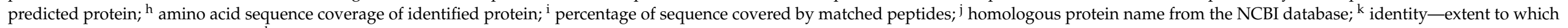
two amino acid sequences match; ${ }^{1}$ positives-similarities based on scoring matrix. 
Using the information from the UniProt database, we assigned the biological function (Figure 2a) and subcellular location (Figure 2b) to the identified proteins. Some proteins were assigned to more than one subcellular location, which was reflected in the plots.
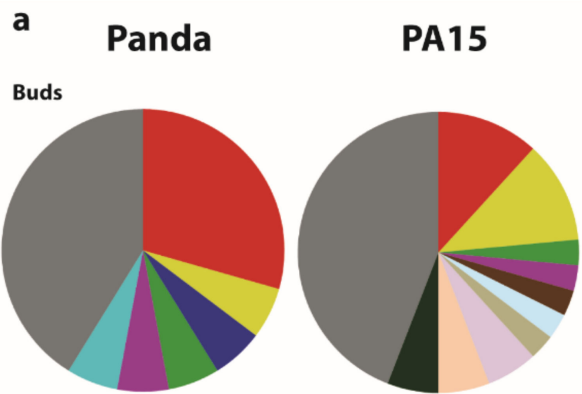

Open flowers
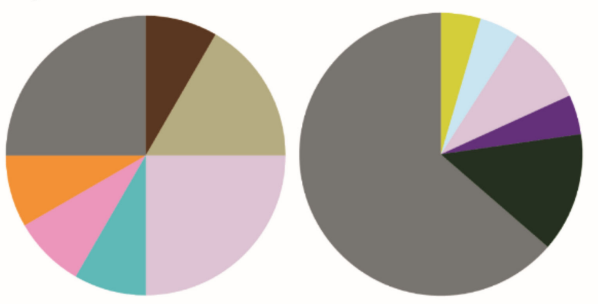

Wilted flowers
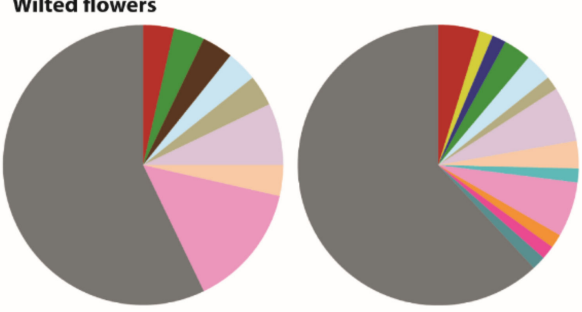

Leaves

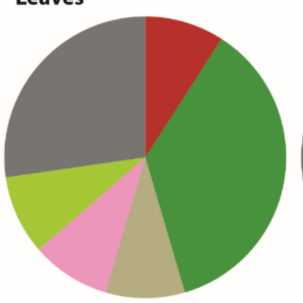

- Protein synthesis

Cytoskeleton organization

- Secondary metabolite biosynthesis

- Photosynthesis

- Lipid metabolism

- Signalling

Transport

- Amino acid biosynthesis

- Carbohydrate metabolism

Protein degradation

- DNA rapair

- Stress response

- Cell cycle

- Storage protein

- Unknown

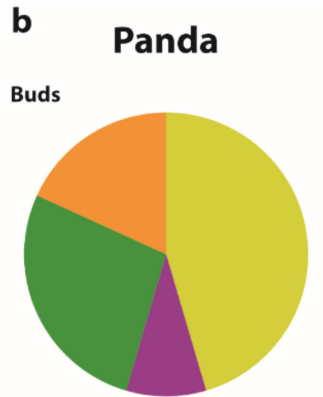

b Panda

PA15

Open flowers

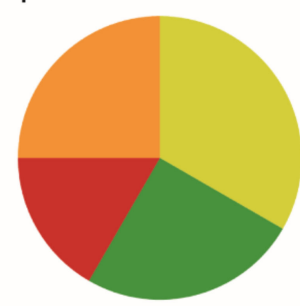

Wilted flowers
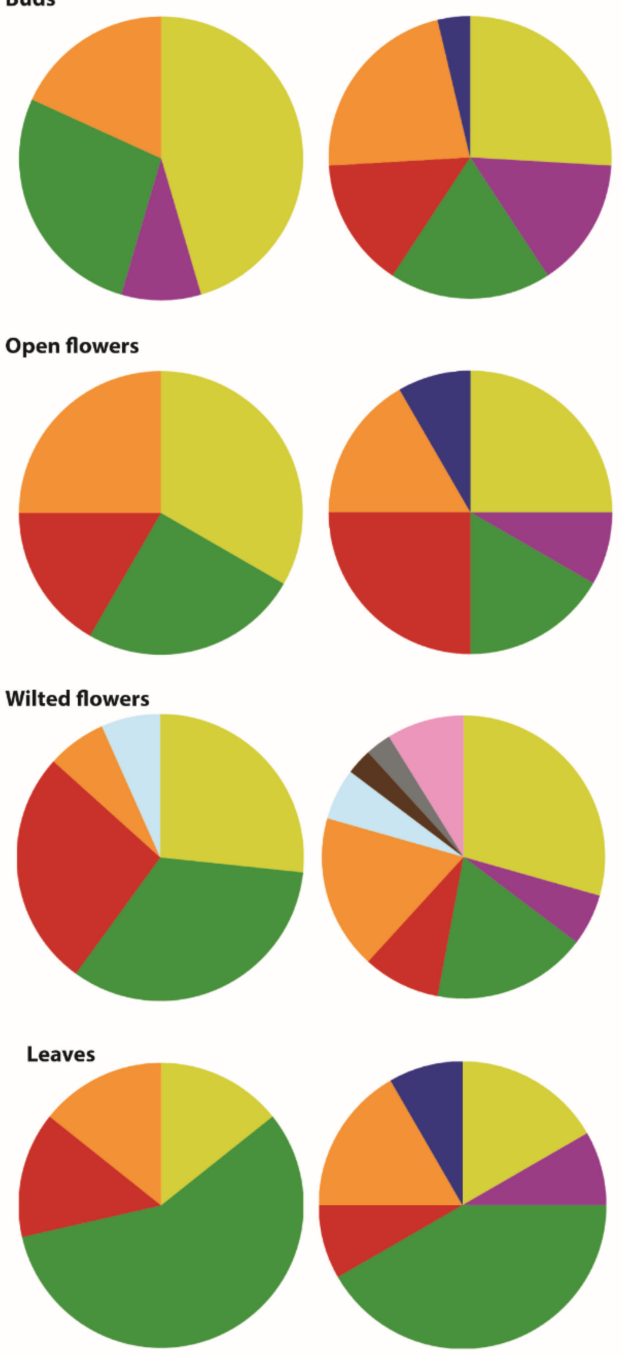

Cytosol

- Cytoskeleton

- Mitochondrion

- Protein modyfication

- Cell wall biogenesis

- Chromatin organization

- Pigment biosynthesis
Chloroplast

Membrane

Nucleus
Vacuole

- Golgi aparatus

- Cell wall

- Apoplast

Figure 2. Composite graph showing heat-affected proteins in different organs of Panda and PA15 buckwheat accessions: (a) Biological functional categorization of heat-affected proteins; (b) distribution of identified proteins according to subcellular location; proteins with two and more localizations in the cell were assigned to all places. Biological function and subcellular localization were assigned based on information in the UniProt database. 
In flower buds, heat stress mainly caused an increase in the abundance of cytosollocalized proteins related to protein synthesis. In Panda, these were mainly ribosomal proteins, whereas in PA15, two out of four proteins were transcription factors. Other heat-affected proteins in PA15 were related to organization of the cytoskeleton. Three proteins were up-regulated by heat stress in both Panda and PA15: two proteins involved in protein synthesis (60S ribosomal protein L5-1 and trihelix transcription factor GTL2) and one involved in lipid metabolism (acyl-[acyl-carrier-protein] desaturase 6).

For open flowers, the majority of the proteins showing changes in abundance under heat stress were related to carbohydrate metabolism in Panda, and protein modification in PA15 (Figure 2a). In Panda, most of the heat-affected proteins were localized to the cytosol, but some were localized to the chloroplast, plasma membrane, and nucleus (Figure 2b). In PA15, more of the heat-affected proteins were localized to the plasma membrane than to the cytosol, cytoskeleton, chloroplasts, mitochondria, and nucleus. Only one protein in open flowers, 6-phosphogluconate dehydrogenase, was up-regulated by heat stress in both buckwheat accessions. This enzyme is involved in the pentose phosphate pathway. Among all of the heat-affected proteins, indole-3-glycerol phosphate synthase showed the largest increase in abundance under heat stress. In Panda, its abundance in open flowers of plants grown at $30^{\circ} \mathrm{C}$ was 213 -fold that in plants grown at $20^{\circ} \mathrm{C}$. This enzyme is involved in the biosynthesis of the precursor of indole ring-containing compounds. It was identified using the BLASTP program on the basis of its homology to indole-3-glycerol phosphate synthase in Acidithiobacillus ferrooxidans.

Only a few of the heat-affected proteins in wilted flowers were identified. The identified proteins were mainly involved in the stress response (Figure 2a). Two $70 \mathrm{kDa}$ heatshock proteins and the glutamate receptor 3.4 were up-regulated by heat stress in wilted flowers of both buckwheat accessions. The other common proteins were chaperone protein ClpC, V-type proton ATPase catalytic subunit A, calpain-type cysteine protease DEK1, phosphoglycerate kinase, and fructose-bisphosphate aldolase 2. In PA15, several proteins related to carbohydrate metabolism were up-regulated under heat stress. The identified heat-affected proteins in wilted flowers of Panda were mainly localized in chloroplasts, while those in PA15 were mainly localized in the cytosol (Figure 2b).

In the donor leaves, high temperature up-regulated proteins related to photosynthesis in Panda (Figure 2a). Most of the identified heat-affected proteins in the donor leaves of Panda and PA15 were localized in the chloroplast (Figure 2b). Many of the heat-affected proteins in the donor leaves of PA15 were not identified, but most of the identified proteins were involved in amino acid biosynthesis. The cytosol-localized enzyme S-adenosylmethionine synthase showed changes in abundance in donor leaves in both accessions under heat stress.

All results obtained in this experiment are summarized in detail in Table S1.

\section{Discussion}

A central role in plant thermotolerance is played by reactive oxygen scavenging enzymes, heat-shock proteins (HSPs), and heat stress-responsive transcription factors (HSFs), which induce expression of HSPs, signal and regulatory proteins, proteins involved in metabolism, and redox homeostasis. The plant's response to heat stress involves the heat-shock transcription factor A1 (HsfA1) that is indispensable in the activation of transcriptional networks. It is responsible for regulating the level of transcription factors expression, including the dehydration-responsive element binding protein 2A (DREB2A). However, the activity of HsfA1 is regulated by interaction with HSPs [26,27].

In this study, we explored the effect of heat stress on protein expression in two accessions of buckwheat, Panda and PA15. The total protein content increased under heat stress in both buckwheat accessions, but none of the proteins were newly expressed in response to heat stress. Up-regulation of protein expression may indicate a positive effect of high temperature on vegetative and reproductive development. However, the two studied accessions responded differently to heat stress, as illustrated by their different proteomes. 
In all organs, heat stress up-regulated more proteins in PA15 than in Panda. In our previous studies, the different responses of these accessions' to heat stress were also reflected in the content of hormones [9] and HSP-70 and HSP-90 proteins [28] in their flowers and leaves.

Characteristic protein spots for the large Rubisco subunit were observed in the 2-D gels of proteins extracted from buds, open flowers, and wilted flowers. We also detected some chloroplast-localized proteins related to photosynthesis, because the floral tissues that the proteins were extracted from included the green pedicel. To identify proteins from gel spots we used nanoLC-MS/MS. It is the most adequate method used for this purpose, but may not be of use for low-abundant proteins [29]. In many cases, the analyzed sample had insufficient protein concentration; therefore, in the second attempt, the proteins were identified using the PMF technique. The PMF method requires less protein and is also much cheaper, but has many limitations that influenced the number of proteins identified in the experiment. The method fails to identify mixture proteins, low molecular mass proteins, and protein fragments. Additionally, PMF raises problems with the identification of large proteins. The success of the analysis is also determined by the presence of the protein sequences of interested search in the database [30]. In our experiment, among the proteins identified, none were specific to common buckwheat. All of them were homologous to proteins in different species. Similar results were presented by other authors when studying poorly known species [31]. In future studies on the buckwheat proteome in protein identification, a buckwheat genome database should be included [32]. This approach will allow to identify even proteins that we have not been able to identify so far. However, a potential change in the identification methods used would not change the overall picture obtained in our study and thus the conclusions drawn from our research on buckwheat response to heat stress. On the other hand, a change in methodology could be useful if the aim of our work was to identify candidate genes for high temperature stress tolerance.

Four proteins were up-regulated by heat stress in the flower buds of both accessions. These proteins included acyl-[acyl-carrier-protein] (ACP) desaturase 6, 60S ribosomal protein L5-1, and the trihelix transcription factor GTL2. ACP desaturase 6 is localized in the chloroplasts. It is responsible for unsaturated fatty acid biosynthesis, and its role is to introduce a double bond during esterification of the acyl group to the acyl carrier protein. Derivatives of unsaturated fatty acids (UFA) are known to function as signaling molecules in responses to various stresses. High temperature has been shown to increase the UFA content in olive plants [33]. Changes to the UFA content have been shown to affect the stress response, and result in changes in salicylic acid (SA)- and jasmonic acid (JA)-mediated defense responses, especially to biotic stresses [34]. In our previous study, we found that high temperature led to increased SA contents in buds of Panda and PA15, but decreased the contents of JA and its methyl ester (JA-Met) in both accessions [9]. The other two identified proteins induced by heat stress in the two accessions were related to protein synthesis pathways. The 60S ribosomal protein L5-1 is a component of the ribosome, whereas the trihelix transcription factor GTL2 binds to a specific DNA sequence to regulate gene transcription. Magwanga et al. [35] also found that the trihelix transcription factor GTL2 was highly up-regulated in cotton under drought and salt stress conditions.

In open flowers, only 6-phosphogluconate dehydrogenase (6PGDH) was up-regulated by heat stress in both buckwheat accessions. This enzyme plays a key role in the oxidative pentose phosphate pathway (OPPP), which is critical for maintaining redox balance under stress situations. 6PGDH probably controls the efficiency of this pathway. In rice, expression of the gene encoding 6PGDH was found to be up-regulated by abscisic acid (ABA) treatment [36]. In our previous study, we found that the free ABA content in open flowers increased in Panda and decreased in PA15 under heat stress. However, the concentration of the conjugate ABA-glc increased in PA15 but remained stable in Panda under heat stress [9].

Heat stress resulted in a dramatic increase in the abundance of one protein spot in the open flowers of Panda (to 213 times that in control plants grown at $20^{\circ} \mathrm{C}$ ). We identified this 
protein as the indole-3-glycerol phosphate synthase (IGPS) chloroplastic-like isoform X2. This enzyme produces indole-3-glycerol phosphate (IGP) as the precursor of indole ringcontaining compounds and participates in the biosynthesis of tryptophan, indole 3-acetic acid, phytoalexin alkaloids, and glucosinolates. Indole plays roles in abiotic and biotic stress responses, but also in flowers, where it is emitted as a scent to attract pollinators [37]. IGP may be a branchpoint compound in the tryptophan-independent and tryptophandependent auxin biosynthetic pathways [38]. Auxins are responsible for plant fertility and high temperatures reduce plant fertility through repression of expression of the YUCCA auxin biosynthesis genes [39]. YUCCA (YUC)-type flavin-containing monooxygenases catalyze a reaction whose product is indole 3-acetic acid [40]. Thus, in this context, it can be speculated that the increase in IGPS accumulation in the flowers of the heat-sensitive Panda may be an attempt to counteract the reduction in auxin content in heat-treated flowers observed in this accession in contrast to the tolerant PA15, where this decrease was lower [9]. It is possible that one of the possible heat-tolerance mechanism in PA15 is the lower heat-sensitivity of some elements of auxin biosynthesis pathway.

Few of the proteins showing heat-induced changes in abundance in wilted flowers were identified, especially those in PA15. Many of the protein spots on the 2-D gels of proteins from wilted flowers were probably protein fragments resulting from an increase in proteolytic enzyme activity and limited repair mechanisms. Wilted flowers were aborted due to a lack of pollination. Proteins can be fragmented by reactive oxygen species (ROS) and proteolytic enzymes. Heat stress accelerates the generation and reactions of ROS, and senescing tissues do not have an efficient antioxidant system [41]. In wilted flowers, nine protein spots accumulated under heat stress in both accessions. One of them could not be identified. Two spots were identified as HSP-70s. Members of the HSP-70 family function as chaperones to facilitate protein folding, degradation, complex assembly, and translocation. They play a key role in stabilizing proteins under optimal and stress conditions [42]. Previously, we detected the accumulation of HSP-70 and HSP-90 in buckwheat flowers at various stages of development [28]. Moreover, we identified the chaperone protein $\mathrm{ClpC}$ in the HSP-100 family that plays a vital role in chloroplast function [43]. The presence of HSP-70 and HSP-100 proteins suggests that certain defense mechanisms function in wilted flowers, but they may be involved in the proper degeneration of the organ. Another protein expressed under heat stress in both Panda and PA15 was the V-type proton ATPase (V-ATPase) catalytic subunit A, which is a component of the membrane-bound V-ATPase located at the tonoplast and other sites in the endomembrane system of plant cells. The abundance of V-ATPase subunits is known to be modulated by environmental stresses [44]. Another heat-affected protein in wilted flowers was the calpain-type cysteine protease DEK1, the only calpain protein in plants. This protein is essential for embryo development [45]. The glutamate receptor 3.4 was also commonly up-regulated by heat stress in both accessions. This protein is a component of the glutamate receptor-like channel (GLR). GLRs play a role in calcium signaling during the response to environmental stresses [46]. Two proteins up-regulated by heat stress in wilted flowers were involved in carbohydrate metabolism: cytosolic phosphoglycerate kinase (PGK) and chloroplastic fructose-bisphosphate aldolase (FBA). Cytosolic PGK is involved in glycolysis and gluconeogenesis. Plants also have plastidial isoforms of PGK that may simultaneously participate in the Calvin-Benson cycle and glycolytic/gluconeogenic reactions [47]. Chloroplastic FBA is a bifunctional enzyme involved in the formation of fructose-1,6-bisphosphate (FBP) and sedoheptulose-1,7-bisphosphate (SuBP) in the Calvin cycle. It also functions as a sedoheptulose/fructose-bisphosphate aldolase (SFBA). FBA aldolase activity, but not SuBP activity, is important for glycolytic and gluconeogenetic reactions in the cytoplasm [48].

In donor leaves, only $S$-adenosylmethionine synthetase (SAMS) was up-regulated by heat stress in both buckwheat accessions. This enzyme synthesizes $S$-adenosylmethionine (SAM) from ATP and L-methionine. It is involved in the biosynthesis of ethylene, nicotiamine, and polyamines. It represents the major hub of the methionine metabolism and participates in plant responses to environmental stresses [49]. 


\section{Materials and Methods}

\subsection{Plant Material and Growth Conditions}

Seeds of common buckwheat (Fagopyrum esculentum Moench), the Polish cultivar Panda and the PA15 strain, were supplied by Małopolska Plant Breeding (Polanowice, Poland), and were produced at the plant production facility in Palikije. Panda is more sensitive to heat stress than PA15 is, as manifested by the degeneration of a large number of embryo sacs [9]. The plant growth conditions in the phytotron have been described in our previous papers $[8,9]$. Plants were cultivated in plastic pots of $10 \mathrm{dm}^{3}$ capacity (six plants per pot) filled with a mixture of commercial soil substrate $(\mathrm{pH}=5.8)$ and perlite $(1: 1$, v:v) under a $16 \mathrm{~h}$ photoperiod and $300 \mu \mathrm{mol} \mathrm{m}^{-2} \mathrm{~s}^{-1}$ (High-Pressure Sodium, HPS lamps, SON-T+ AGRO, Philips, Brussels, Belgium) at a humidity of 50-60\%. For the first 3 weeks, all plants were grown at $20^{\circ} \mathrm{C}$, and then half of them were transferred to a chamber at $30^{\circ} \mathrm{C}$ (heat stress) with the same humidity and light conditions. When the plants were 2 months old, we collected flowers at three developmental phases (buds, open flowers, and wilted flowers) and donor leaves (fully developed young leaves closest to the flower cluster) from plants in the control and heat stress treatments. The experiment was repeated twice. The samples were immediately frozen in liquid nitrogen and then stored at $-80{ }^{\circ} \mathrm{C}$ until subsequent analysis. Protein extraction and electrophoretic separation were performed from three aggregate replicates for each development phase of flowers and donor leaves, for both accessions in both temperature treatments.

\subsection{Protein Extraction}

Total proteins were extracted using a phenol-based procedure [50] (modified by Hajduch et al. [51]). Buckwheat tissues were pulverized into a fine powder in liquid nitrogen with a mortar and pestle. The powder was suspended in $10 \mathrm{~cm}^{3}$ of a phenolbased extraction buffer (50\% [v/v] phenol, $0.45 \mathrm{M}$ sucrose, $5 \mathrm{mM}$ EDTA, $0.4 \%$ [v/v] 2mercaptoethanol, $50 \mathrm{mM}$ Tris- $\mathrm{HCl} \mathrm{pH} \mathrm{8.8).} \mathrm{The} \mathrm{homogenate} \mathrm{was} \mathrm{allowed} \mathrm{to} \mathrm{reach} \mathrm{room}$ temperature, transferred to a Falcon tube, and shaken for $30 \mathrm{~min}$. The phenol and aqueous phases were separated by centrifugation $\left(5000 \mathrm{~g}, 15 \mathrm{~min}, 4^{\circ} \mathrm{C}\right)$. Proteins were precipitated with five volumes of ice-cold $0.1 \mathrm{M}$ ammonium acetate in $100 \%$ methanol at $-20{ }^{\circ} \mathrm{C}$ for $16 \mathrm{~h}$. After centrifugation $\left(5000 \times \mathrm{g}, 10 \mathrm{~min}, 4^{\circ} \mathrm{C}\right)$, the protein pellet was washed twice with the precipitation solution, then with $80 \%$ acetone, and then with $70 \%$ ethanol. The total protein extracts were dissolved in $200 \mu \mathrm{L}$ isolectricfocusing (IEF) sample solution (8 M urea, $2 \mathrm{M}$ thiourea, $4 \%(w / v)$ 3-[(3-Cholamidopropyl)dimethylammonio]-1-propanesulfonate (CHAPS), $50 \mathrm{mM}$ dithiothreitol (DTT)) by shaking for $1 \mathrm{~h}$. The protein concentration was determined using a 2D Quant Kit (GE Healthcare, Piscataway, NJ, USA). Protein extracts in the IEF sample solution were stored at $-80{ }^{\circ} \mathrm{C}$ until analysis.

\subsection{Two-Dimensional Gel Electrophoresis}

Two-dimensional gel electrophoresis (2-DE) was based on the procedure recommended by GE Healthcare. The desired amount of protein $(700 \mathrm{mg})$ was mixed with $4.6 \mu \mathrm{L}$ IPG buffer (pH range 4-7) (GE Healthcare), adjusted to $450 \mu \mathrm{L}$ with IEF sample solution, and loaded onto a $24 \mathrm{~cm}$ immobilized $\mathrm{pH}$ gradient strip (Immobiline DryStrip gel; GE Healthcare) with a linear $\mathrm{pH}$ range of 4-7. The strips were passively rehydrated in a DryStrip IPGbox (GE Healthcare) for $16 \mathrm{~h}$. The first dimension of isoelectrofocusing (IEF) was carried out using an Amersham Ettan IPGphor II unit (GE Healthcare). The six-step focusing protocol with a current limit of $75 \mu \mathrm{A}$ per strip was as follows: (a) $45 \mathrm{Vh}$ at $150 \mathrm{~V}$, (b) $375 \mathrm{Vh}$ at $150 \mathrm{~V}$, (c) $500 \mathrm{Vh}$ at $500 \mathrm{~V}$; (d) $800 \mathrm{Vh}$ at $1000 \mathrm{~V}$; (e) 16,500 Vh at 10,000 V; (f) $27,200 \mathrm{Vh}$ at $10,000 \mathrm{~V}$. After IEF, the strips were incubated in an equilibration buffer (1.5 M Tris- $\mathrm{HCl} \mathrm{pH} 8.8,6 \mathrm{M}$ urea, $30 \%(v / v)$ glycerol, $5 \%(w / v)$ sodium dodecyl sulfate (SDS)) for 15 min with $2 \%(w / v)$ dithiothreitol (DTT) and then for another 15 min with $2.5 \%(w / v)$ iodoacetamide. After equilibration, each strip was placed onto a 12\% SDS-polyacrylamide gel and then overlaid with $0.5 \%(w / v)$ agarose in an SDS running buffer with Coomassie Brilliant Blue G-250 as the tracking dye. Separation on the second dimension was per- 
formed using an SE900 Large Format Vertical Gel Protein Electrophoresis Unit (Hoefer Scientific Instruments, San Francisco, CA, USA) at $48 \mathrm{~W}$ per gel until the dye migrated off the gel. After electrophoresis, each gel was washed three times for 15 min each time in deionized water and then stained overnight in colloidal Coomassie staining solution $(20 \%(v / v)$ ethanol, $1.6 \%(v / v)$ phosphoric acid, $8 \%(w / v)$ ammonium sulfate, $0.08 \%(w / v)$ Coomassie Brilliant Blue G-250) using the modified method of Neuhoff et al. [52].

\subsection{Gel Image Analysis}

Stained 2-DE gels were digitalized using an Epson Perfection V850 Pro scanner at a resolution of 300 dpi and 16-bit gray scale pixel depth. Gel images were analyzed using Delta2D software (Decodon, Greifswald, Germany). The volume of the spots was normalized against the total volume of all spots in the analysis. The $t$ test value for each spot was calculated using Delta2D software. Only spots with a $p$-value lower than or equal to 0.05 were considered to be differentially expressed. Spots with at least 2.0 -fold differences in protein abundance between two treatments were chosen for further analysis.

\subsection{Protein Identification}

The protein spots were manually selected and excised from the gels for identification. First, proteins were analyzed by liquid chromatography-mass spectrometry (nanoLCMS/MS). If proteins could not be identified by nanoLC-MS/MS, peptide mass fingerprinting (PMF) analysis was performed. Mass spectrometry analysis was performed at the Laboratory of Proteomics and Mass Spectrometry, Maj Institute of Pharmacology, Polish Academy of Sciences, Kraków (Poland).

The excised protein spots were prepared for mass spectrometry analysis according to the protocol described by Hartman et al. [53]. The gel pieces in tubes were incubated at $40{ }^{\circ} \mathrm{C}$ in $100 \mathrm{mM}$ ammonium bicarbonate for $10 \mathrm{~min}$. Then, acetonitrile was added to a final concentration of $50 \%(v / v)$ and the mixture was incubated at $40{ }^{\circ} \mathrm{C}$ for $10 \mathrm{~min}$. After incubation, the solution was removed. The washing step was repeated three times to remove all Coomassie dye, until the gels were completely colorless. Finally, the gels were dehydrated in anhydrous acetonitrile. The acetonitrile was removed, and then the dry gel pieces were reswollen in $25 \mu \mathrm{L} 50 \mathrm{mM}$ DTT dissolved in $100 \mathrm{mM}$ ammonium bicarbonate, followed by incubation at $60{ }^{\circ} \mathrm{C}$ for $45 \mathrm{~min}$. Then, the DTT solution was replaced with $25 \mu \mathrm{L} 100 \mathrm{mM}$ iodoacetamide in $100 \mathrm{mM}$ ammonium bicarbonate. The gel pieces were incubated at room temperature in darkness for $20 \mathrm{~min}$, then $25 \mu \mathrm{L} 10 \mathrm{ng} \mu \mathrm{L}^{-1}$ trypsin Gold (Promega, Madison, WI, USA) solution in $100 \mathrm{mM}$ ammonium bicarbonate was added and the gel pieces were incubated at $4{ }^{\circ} \mathrm{C}$ for $1 \mathrm{~h}$. Then, $25 \mu \mathrm{L} 50 \mathrm{mM}$ ammonium bicarbonate solution was added and the gel pieces were incubated overnight at $37^{\circ} \mathrm{C}$. The next day, the supernatant containing the digested peptides was collected in a new tube and combined with subsequent fractions. The gel pieces were immersed in $50 \mathrm{mM}$ ammonium bicarbonate and incubated at $40{ }^{\circ} \mathrm{C}$ for $10 \mathrm{~min}$ before adding acetonitrile to a final concentration of $50 \%(v / v)$. The resulting supernatants were collected. Further extraction of peptides was performed in acidic conditions by incubation with $5 \%(v / v)$ formic acid in $50 \%(v / v)$ acetonitrile, twice. The gel pieces were dehydrated in anhydrous acetonitrile. Combined solutions from one sample were dried and dissolved in $20 \mu \mathrm{L} 0.1 \%$ formic acid and then analyzed by nanoLC-MS/MS and PMF.

The nanoLC-MS/MS analyses were performed using an Easy-nLC II nano capillary chromatography system (Bruker Daltonics, Bremen, Germany) as described in Drabik et al. [54]. Peptides were separated on a $3 \mu \mathrm{m}$ Biosphere C18 column $(10 \mathrm{~cm}$ long, $75 \mu \mathrm{m}$ internal diameter; Nanoseparations, Nieuwkoop, The Netherlands). The gradient was formed using two mobile phases: Phase A: $0.1 \%$ formic acid in water; phase B: $0.1 \%$ formic acid in acetonitrile. The total flow rate was $300 \mathrm{nl} \mathrm{min}^{-1}$. The system was controlled using Hystar software (Bruker Daltonics). The gradient program was as follows: from $2 \%$ to $45 \%$ Phase B in $30 \mathrm{~min}$, then $90 \%$ Phase B for $10 \mathrm{~min}$, decreasing to $2 \%$ Phase B until $60 \mathrm{~min}$ for column equilibration. Fractions eluted from the column were directly deposited 
with a w matrix on the MALDI target plate by a Proteineerfc II sample collector (Bruker Daltonics). Fractions were collected at $15 \mathrm{~s}$ intervals. Samples made up of 96 fractions were spotted on a 384 MALDI target plate. $\alpha$-Cyano-4-hydroxycinnamic acid was used as the MALDI matrix. The mass spectrometry analyses were performed on an Ultraflextreme instrument (Bruker Daltonics) in the positive ion mode.

Samples for PMF analysis were bound to C18 resin in ZipTip columns (Supel-Tips C18 PipetteTips, Supelco/Sigma-Aldrich, Bellefonte PA, USA) according to the manufacturer's instructions. The peptides were eluted from the column with saturated $\alpha$-cyano-4hydroxycinnamic acid solution in $60 \%(v / v)$ acetonitrile with $0.1 \%(v / v)$ trifluoroacetic acid directly on the MALDI target plate.

The acquired mass spectra and fragment mass spectra (for both LC-MS and PMF) were analyzed using FlexAnalysis software (Version: 3.4, Bruker Daltonics) and ProteinScape (Version: 3.0.0 446, Bruker Daltonics) and were processed using the Mascot algorithm (Engine version: 2.3, Matrix Science) against the SwissProt_2015_04 database. The searches were performed with the following parameters: Cerbamidomethylation of cysteine as a fixed modification; oxidation of methionine as an allowable variable modification; up to 1 missed cleavage allowed; $25 \mathrm{ppm}$ for precursor mass tolerance; $0.6 \mathrm{Da}$ for MS/MS mass tolerance; peptide charge: 1+ for PMF (MALDI-TOF instrument-UltrafleXtreme from Bruker Daltonics) and 0.3 Da for precursor mass tolerance; 0.6 Da for MS/MS mass tolerance; peptide charge: 2+,3+, 4+ for LC-MS (ESI-IT instrument on an Amazon SL from Bruker Daltonics) analyses. The database search was run against the protein database Viridiplantae (563,552 sequences; 203,007,781 residues; May 2020). If no protein was identified, the database was searched for all taxa. Proteins with a mascot score higher than 30 and with a level of false positives of $p \leq 0.05$ were considered as identified. In cases where the identified protein belonged to an organism other than plants, a search was performed based on the amino acid sequence of the homologous protein among green plants using BLASTP (https:/ / blast.ncbi.nlm.nih.gov).

\section{Conclusions}

Two common buckwheat accessions, Panda and PA15, differ in their tolerance to high temperature, as illustrated by the frequency of embryo sac degradation under heat stress. The different responses of the two accessions to heat stress were reflected in their protein profiles. All heat-affected proteins showed up-regulated expression in the organs of the two accessions. Many proteins could not be identified. It is possible that some protein spots were protein fragments resulting from proteolysis and inadequate repair mechanisms. There were more heat-affected proteins in PA15, the heat-tolerant accession, than in Panda, the heat-sensitive accession. Surprisingly, only a few proteins were commonly up-regulated by heat in both accessions. Plants' tolerance to heat stress, as to other environmental stresses, is the sum of minor and major changes in the proteome, and cannot be explained by single changes. Proteins common to both accessions characterize the heat-affected protein profile of common buckwheat. The abundance of indole-3-IGPS chloroplastic-like isoform X2 increased markedly in open flowers of Panda under heat stress. This may be a candidate protein to serve as a marker of sensitivity of buckwheat plants to heat stress.

Supplementary Materials: The following are available online at https:/ / www.mdpi.com/1422-006 7/22/5/2678/s1, Table S1: List of heat-affected proteins in buds, open flowers, wilted flowers, and donor leaves of common buckwheat accessions Panda and PA15; comparison of protein abundance between heat-treated plants and those growing in optimal conditions.

Author Contributions: Conceptualization, A.P., P.K., M.H.; methodology, P.K.; performing the experiment, P.K., M.H., J.P., A.S., J.W.; data analysis, P.K.; writing-original draft preparation, P.K., A.P., M.H., M.R.; writing—review and editing, M.R.; project leader, A.P. All authors have read and agreed to the published version of the manuscript.

Funding: This study was supported by funding from the National Centre of Knowledge of Poland (No. 2017/25/B/NZ9/00148). 
Institutional Review Board Statement: Not applicable.

Informed Consent Statement: Not applicable.

Data Availability Statement: The data supporting the findings of this study are available from the corresponding author upon reasonable request.

Acknowledgments: We thank the staff at the Laboratory of Proteomics and Mass Spectrometry, Maj Institute of Pharmacology, Polish Academy of Sciences, Krakow, for assistance with protein identification. We thank Przemysław Mielczarek from Maj Institute of Pharmacology PAS for technical support and Jennifer Smith from Edanz Group for editing the English text of draft of this manuscript.

Conflicts of Interest: The authors declare no conflict of interest.

$\begin{array}{ll}\text { Abbreviations } \\ \text { 2-DE } & \text { Two-dimensional gel electrophoresis } \\ \text { 6PGDH } & \text { 6-phosphogluconate dehydrogenase } \\ \text { ABA } & \text { Abscisic acid } \\ \text { ACP } & \text { Acyl-[acyl-carrier-protein] } \\ \text { CHAPS } & \text { 3-[(3-cholamidopropyl)dimethyl-ammonio]-1-propane sulfonate } \\ \text { DREB2A } & \text { Dehydration-responsive element binding protein 2A } \\ \text { DTT } & \text { Dithiothreitol } \\ \text { FBA } & \text { Fructose-bisphosphate aldolase } \\ \text { FBP } & \text { Fructose-1,6-bisphosphate } \\ \text { GLR } & \text { Glutamate receptor-like channel } \\ \text { HSF } & \text { Heat-shock transcription factor } \\ \text { HsfA1 } & \text { Heat-shock transcription factor A1 } \\ \text { HSP } & \text { Heat-shock proteins } \\ \text { IEF } & \text { Isoelectricfocusing } \\ \text { IGP } & \text { Indole-3-glycerol phosphate } \\ \text { IGPS } & \text { Indole-3-glycerol phosphate synthase } \\ \text { JA } & \text { Jasmonic acid } \\ \text { JA-Met } & \text { Methyl ester of jasmonic acid } \\ \text { OPPP } & \text { Oxidative pentose phosphate pathway } \\ \text { PGK } & \text { Phosphoglycerate kinase } \\ \text { PMF } & \text { Peptide mass fingerprinting } \\ \text { ROS } & \text { Reactive oxygen species } \\ \text { SA } & \text { Salicylic acid } \\ \text { SAM } & \text { S-adenosylmethionine } \\ \text { SAMS } & \text { S-adenosylmethionine synthetase } \\ \text { SDS } & \text { Sodium dodecyl sulfate } \\ \text { SFBA } & \text { Sedoheptulose/ fructose-bisphosphate aldolase } \\ \text { SuBP } & \text { Sedoheptulose-1,7-bisphosphate } \\ \text { TF } & \text { Transcription factor } \\ \text { UFA } & \text { Unsaturated fatty acids } \\ \text { V-ATPase } & \text { V-type proton ATPase } \\ & \end{array}$

\section{References}

1. Christa, K.; Soral-Smietana, M. Buckwheat grains and buckwheat products-Nutritional and prophylactic value of their components-A review. Czech J. Food Sci. 2008, 26, 153-162. [CrossRef]

2. Halbrecq, B.; Romedenne, P.; Ledent, J.F. Evolution of flowering, ripening and seed set in buckwheat (Fagopyrum esculentum Moench): Quantitative analysis. Eur. J. Agron. 2005, 23, 209-224. [CrossRef]

3. Farooq, S.; Rehman, R.U.; Pirzadah, T.B.; Malik, B.; Dar, F.A.; Tahir, I. Cultivation, agronomic practices, and growth performance of buckwheat. In Molecular Breeding and Nutritional Aspects of Buckwheat; Zhou, M., Kreft, I., Woo, S.H., Chrungoo, N., Wieslander, G., Eds.; Academic Press: Oxford, UK, 2016; pp. 299-320. [CrossRef]

4. Cawoy, V.; Ledent, J.-F.; Kinet, J.-M.; Jacquemart, A.-L. Floral biology of common buckwheat (Fagopyrum esculentum Moench). Eur. J. Plant Sci. Biotechnol. 2009, 3, 1-9. 
5. Adachi, T. How to combine the reproductive system with biotechnology in order to overcome the breeding barrier in buckwheat. Fagopyrum 1990, 10, 1.

6. Slawinska, J.; Obendorf, R.L. Buckwheat seed set in planta and during in vitro inflorescence culture: Evaluation of temperature and water deficit stress. Seed Sci. Res. 2001, 11, 223-233. [CrossRef]

7. Słomka, A.; Michno, K.; Dubert, F.; Dziurka, M.; Kopeć, P.; Plażek, A. Embryological background of low seed set in distylous common buckwheat (Fagopyrum esculentum Moench) with biased morph ratios, and biostimulant-induced improvement of it. Crop Pasture Sci. 2017, 68, 680-690. [CrossRef]

8. Hornyák, M.; Płazek, A.; Kopeć, P.; Dziurka, M.; Pastuszak, J.; Szczerba, A.; Hura, T. Photosynthetic activity of common buckwheat (Fagopyrum esculentum Moench) exposed to thermal stress. Photosynthetica 2020, 58, 45-53. [CrossRef]

9. Płażek, A.; Słomka, A.; Kopeć, P.; Dziurka, M.; Hornyák, M.; Sychta, K.; Pastuszak, J.; Dubert, F. Effects of high temperature on embryological development and hormone profile in flowers and leaves of common buckwheat (Fagopyrum esculentum Moench). Int. J. Mol. Sci. 2019, 20, 5. [CrossRef]

10. Timperio, A.M.; Egidi, M.G.; Zolla, L. Proteomics applied on plant abiotic stresses: Role of heat shock proteins (HSP). J. Proteom. 2008, 71, 391-411. [CrossRef]

11. Kosová, K.; Vítámvás, P.; Prášil, I.T.; Renaut, J. Plant proteome changes under abiotic stress: Contribution of proteomics studies to understanding plant stress response. J. Proteom. 2011, 74, 1301-1322. [CrossRef]

12. Lee, D.-G.; Ahsan, N.; Lee, S.-H.; Kang, K.Y.; Bahk, J.D.; Lee, I.-J.; Lee, B.-H. A proteomic approach in analyzing heat-responsive proteins in rice leaves. Proteomics 2007, 7, 3369-3383. [CrossRef]

13. Mittler, R.; Zilinskas, B.A. Molecular cloning and characterization of a gene encoding pea cytosolic ascorbate peroxidase. J. Biol. Chem. 1992, 267, 21802-21807. [CrossRef]

14. Miernyk, J.A. The $70 \mathrm{kDa}$ stress-related proteins as molecular chaperones. Trends Plant Sci. 1997, 2, 180-187. [CrossRef]

15. Renaut, J.; Hausman, J.F.; Wisniewski, M.E. Proteomics and low-temperature studies: Bridging the gap between gene expression and metabolism. Physiol. Plant 2006, 126, 97-109. [CrossRef]

16. Miernyk, J.A.; Pret'ová, A.; Olmedilla, A.; Klubicová, K.; Obert, B.; Hajduch, M. Using proteomics to study sexual reproduction in angiosperms. Sex. Plant Reprod. 2011, 24, 9-22. [CrossRef] [PubMed]

17. Feng, B.; Li, L.; Zhou, X.; Stanley, B.; Ma, H. Analysis of the Arabidopsis floral proteome: Detection of over 2000 proteins and evidence for postrranslational modifications. J. Integr. Plant Biol. 2009, 51, 207-223. [CrossRef] [PubMed]

18. Kerim, T.; Imin, N.; Weinman, J.J.; Rolfe, B.G. Proteome analysis of male gametophyte development in rice anthers. Proteomics 2003, 3, 738-751. [CrossRef]

19. Uchiumi, T.; Shinkawa, T.; Isobe, T.; Okamoto, T. Identification of the major protein components of rice egg cells. Int. J. Plant Res. 2007, 120, 575-579. [CrossRef]

20. Liu, H.; Liu, Y.-Z.; Zheng, S.-Q.; Jiang, J.-m.; Wang, P.; Chen, W. Comparative proteomic analysis of longan (Dimocarpus longan Lour.) seed abortion. Planta 2010, 231, 847-860. [CrossRef]

21. Das, A.; Eldakak, M.; Paudel, B.; Kim, D.-W.; Hemmati, H.; Basu, C.; Rohila, J.S. Leaf proteome analysis reveals prospective drought and heat stress response mechanisms in soybean. Biomed. Res. Int. 2016, 2016. [CrossRef]

22. Rodziewicz, P.; Chmielewska, K.; Sawikowska, A.; Marczak, Ł.; Łuczak, M.; Bednarek, P.; Mikołajczak, K.; Ogrodowicz, P.; Kuczyńska, A.; Krajewski, P.; et al. Identification of drought responsive proteins and related proteomic QTLs in barley. J. Exp. Bot. 2019, 70, 2823-2837. [CrossRef]

23. Singh, P.; Song, Q.-Q.; Singh, R.K.; Li, H.-B.; Solanki, M.K.; Malviya, M.K.; Verma, K.K.; Yang, L.-T.; Li, Y.-R. Proteomic analysis of the resistance mechanism in sugercane during Sporisorium scitamineum infection. Int. J. Mol. Sci. 2019, 20, 569. [CrossRef] [PubMed]

24. Awana, M.; Jain, N.; Samota, M.K.; Rani, K.; Kumar, A.; Ray, M.; Gaikwad, K.; Praveen, S.; Singh, N.K.; Singh, A. Protein and gene integration analysis through proteome and transcriptome brings new insight into salt stress tolerance in pigeonpea (Cajanus cajan L.). Int. J. Biol. Macromol. 2020, 164, 3589-3602. [CrossRef]

25. Li, H.; Li, Y.; Ke, Q.; Kwak, S.-S.; Zhang, S.; Deng, X. Physiological and differential proteomic analysis of imitation drought stress response in Sorghum bicolor root at the seedling stage. Int. J. Mol. Sci. 2020, 21, 9174. [CrossRef] [PubMed]

26. Ohama, N.; Sato, H.; Shinozaki, K.; Yamaguchi-Shinozaki, K. Transcriptional regulatory network of plant heat stress response. Trends Plant Sci. 2017, 22, 53-65. [CrossRef]

27. Janni, M.; Gulli, M.; Maestri, E.; Marmiroli, M.; Valliyodan, B.; Nguyen, H.T.; Marmiroli, N. Molecular and genetic bases of heat stress responses in crop plants and breeding for increased resilience and productivity. J. Exp. Bot. 2020, 71, 3780-3802. [CrossRef]

28. Płażek, A.; Hura, K.; Hura, T.; Słomka, A.; Hornyák, M.; Sychta, K. Synthesis of heat-shock proteins HSP-70 and HSP-90 in flowers of common buckwheat (Fagopyrum esculentum) under thermal stress. Crop Pasture Sci. 2020, 70, 760-767. [CrossRef]

29. Vadivel, A.-K.-A. Gel-based proteomics in plants: Time to move on from the tradition. Front. Plant Sci. 2015, 6, 369. [CrossRef]

30. Thiede, B.; Höhenwarter, W.; Krah, A.; Mattow, J.; Schmid, M.; Schmidt, F.; Jungblut, P.R. Peptide mass fingerprinting. Methods 2005, 35, 237-247. [CrossRef] [PubMed]

31. Bocian, A.; Kosmala, A.; Rapacz, M.; Jurczyk, B.; Marczak, L.; Zwierzykowski, Z. Differences in leaf proteome response to cold acclimation between Lolium perenne plants with distinct levels of frost tolerance. J. Plant Physiol. 2011, 168, 1271-1279. [CrossRef]

32. Yasui, Y.; Hirakawa, H.; Ueno, M.; Matsui, K.; Katsube-Tanaka, T.; Yang, S.J.; Aii, J.; Sato, S.; Mori, M. Assembly pf the draft genome of buckwheat and its applications in identifying agronomically useful genes. DNA Res. 2016, 23, 215-224. [CrossRef] 
33. Hernandez, M.L.; Sicardo, M.D.; Alfonso, M.; Martinez-Rivas, J.M. Transcriptional regulation of stearoyl-acyl carrier protein desaturase genes in response abiotic stresses leads to changes in the unsaturated fatty acids composition of olive mesocarp. Front. Plant Sci. 2019, 10. [CrossRef]

34. Kachroo, A.; Shanklin, J.; Whittle, E.; Lapchyk, L.; Hildebrand, D.; Kachroo, P. The Arabidopsis stearoyl-acyl carrier proteindesaturase family and the contribution of leaf isoforms to oleic acid synthesis. Plant Mol. Biol. 2007, 63, 257-271. [CrossRef]

35. Magwanga, R.O.; Kirungu, J.N.; Lu, P.; Yang, X.; Dong, Q.; Cai, X.; Xu, Y.; Wang, X.; Zhou, Z.; Hou, Y.; et al. Genome wide identification of the trihelix transcription factors and overexpression of Gh_A05G2067 (GT-2), a novel gene contributing to increased drought and salt stresses tolerance in cotton. Physiol. Plant 2019, 167, 447-464. [CrossRef]

36. Hou, F.-Y.; Huang, J.; Yu, S.-L.; Zhang, H.-S. The 6-phosphogluconate dehydrogenase genes are responsive to abiotic stresses in rice. J. Integr. Plant Biol. 2007, 49, 655-663. [CrossRef]

37. Can'ani, A.; Seifan, M.; Tzin, V. Indole is an essential molecule for plant interactions with herbivores and pollinators. J. Plant Biol. Crop Res. 2018, 1, 1003. [CrossRef]

38. Ouyang, J.; Shao, X.; Li, J. Indole-3-glycerol phosphate, a branchpoint of indole-3-acetic acid biosynthesis from tryptohan biosynthetic pathway in Arabidopsis thaliana. Plant J. 2000, 24, 327-333. [CrossRef] [PubMed]

39. Sakata, T.; Oshino, T.; Miura, S.; Tomabechi, M.; Tsunaga, Y.; Higashitani, N.; Miyazawa, Y.; Takahashi, H.; Watanabe, M.; Higashitani, A. Auxins reverse plant male sterility caused by high temperatures. Proc. Natl. Acad. Sci. USA 2010, 107, 8569-8574. [CrossRef]

40. Cao, X.; Yang, H.; Shang, C.; Ma, S.; Liu, L.; Cheng, J. The roles of auxin biosynthesis YUCCA gene family in plants. Int. J. Mol. Sci. 2019, 20, 6343. [CrossRef] [PubMed]

41. Nahar, K.; Hasanuzzaman, M.; Ahamed, K.U.; Hakeem, K.R.; Ozturk, M.; Fujita, M. Plant responses and tolerance to high temperature stress: Role of exogenous phytoprotectants. In Crop Production and Global Environmental Issues; Hakeem, K., Ed.; Springer: Cham, Switzerland, 2015; pp. 385-435. [CrossRef]

42. Landi, S.; Capasso, G.; Ben Azaiez, F.E.; Jallouli, S.; Ayadi, S.; Trifa, Y.; Esposito, S. Different roles of heat shock proteins (70 kDa) during abiotic stresses in barley (Hordeum vulgare) genotypes. Plants 2019, 8, 248. [CrossRef] [PubMed]

43. Sjögren, L.L.; MacDonald, T.M.; Sutinen, S.; Clarke, A.K. Inactivation of the clpC1 gene encoding a chloroplast Hsp100 molecular chaperone causes growth retardation, leaf chlorosis, lower photosynthetic activity, and a specific reduction in photosystem content. Plant Physiol. 2004, 136, 4114-4126. [CrossRef]

44. Ratajczak, R. Structure, function and regulation of the plant vacuolar H+-translocating ATPase. Biochim. Biophys. Acta Biomembr. 2000, 1465, 17-36. [CrossRef]

45. Zhao, S.; Liang, Z.; Demko, V.; Wilson, R.; Johansen, W.; Olsen, O.-A.; Shalchian-Tabrizi, K. Massive expansion of the calpain gene family in unicellular eukaryotes. BMC Evol. Biol. 2012, 12. [CrossRef] [PubMed]

46. Wang, P.-H.; Lee, C.-E.; Lin, Y.-S.; Lee, M.-H.; Chen, P.-Y.; Chang, H.-C.; Chang, I.-F. The glutamate receptor-like protein GLR3. 7 interacts with 14-3-3w and participates in salt stress response in Arabidopsis thaliana. Front. Plant Sci. 2019, 10, 1169. [CrossRef] [PubMed]

47. Rosa-Tellez, S.; Djoro Anoman, A.; Flores-Tornero, M.; Toujani, W.; Alseek, S.; Fernie, A.R.; Nebauer, S.G.; Munoz-Bertomeu, J.; Segura, J.; Ros, R. Phosphoglycerate kinases are co-regulated to adjust metabolism and to optimize growth. Plant Physiol. 2018, 176, 1182-1198. [CrossRef] [PubMed]

48. Lv, G.-Y.; Guo, X.-G.; Xie, L.-P.; Xie, C.-G.; Zhang, X.-H.; Yang, Y.; Xiao, L.; Tang, Y.-Y.; Pan, X.-L.; Guo, A.-G.; et al. Molecular characterization, gene evolution, and expression analysis of the fructose-1, 6-bisphosphate aldolase (FBA) gene family in wheat (Triticum aestivum L.). Front. Plant Sci. 2017, 8. [CrossRef] [PubMed]

49. Heidari, P.; Mazloomi, F.; Nussbaumer, T.; Barcaccia, G. Insights into the SAM synthetase gene family and its roles in tomato seedlings under abiotic stresses and hormone treatments. Plants 2020, 9, 586. [CrossRef]

50. Hurkman, W.J.; Tanaka, C.K. Solubilization of plant membrane proteins for analysis by two-dimensional gel electrophoresis. Plant Physiol. 1986, 81, 802-806. [CrossRef]

51. Hajduch, M.; Ganapathy, A.; Stein, J.W.; Thelen, J.J. A systematic proteomic study of seed filling in soybean. Establishment of high-resolution two-dimensional reference maps, expression profiles, and an interactive proteome database. Plant Physiol. 2005, 137, 1397-1419. [CrossRef]

52. Neuhoff, V.; Arold, N.; Taube, D.; Ehrhardt, W. Improved staining of proteins in polyacrylamide gels including isoelectric focusing gels with clear background at nanogram sensitivity using Coomassie Brilliant Blue G-250 and R-250. Electrophoresis 1988, 9 , 255-262. [CrossRef]

53. Hartman, K.; Mielczarek, P.; Silberring, J. Synthesis of the novel covalent cysteine proteases inhibitor with iodoacetic functional group. Molecules 2020, 25, 813. [CrossRef] [PubMed]

54. Drabik, A.; Ner-Kluza, J.; Mielczarek, P.; Civit, L.; Mayer, G.; Silberring, J. Advances in the study of aptamer-protein target identification using the chromatographic approach. J. Proteome Res. 2018, 17, 2174-2181. [CrossRef] [PubMed] 